\title{
Clinical Reasoning: Where Do We Stand on Identifying and Remediating Difficulties?*
}

\author{
Marie-Claude Audétat ${ }^{1,2}$, Stuart Lubarsky ${ }^{3}$, Jean-Guy Blais ${ }^{4}$, Bernard Charlin ${ }^{2}$ \\ ${ }^{1}$ Department of Family and Emergency Medicine, Faculty of Medicine, University of Montreal, \\ Montreal, Canada \\ ${ }^{2}$ Medical Education and Continuing Professional Development Center (CPASS), Faculty of Medicine, \\ University of Montreal, Montreal, Canada \\ ${ }^{3}$ McGill Center for Medical Education, Faculty of Medicine, McGill University, \\ Montreal, Canada \\ ${ }^{4}$ Department of Administration and Education, Faculty of Education, University of Montreal, Montreal, Canada \\ Email: mcaudetat@sympatico.ca
}

Received March 2 $2^{\text {nd }}, 2013$; revised April $4^{\text {th }}$, 2013; accepted April 12 ${ }^{\text {th }}, 2013$

\begin{abstract}
Copyright (C) 2013 Marie-Claude Audétat et al. This is an open access article distributed under the Creative Commons Attribution License, which permits unrestricted use, distribution, and reproduction in any medium, provided the original work is properly cited.
\end{abstract}

\begin{abstract}
Ten to fifteen percent of medical trainees have academic difficulties, the majority of which are cognitive in nature, including clinical reasoning. Many obstacles impede the rapid identification of clinical reasoning difficulties in medical learners. This article reviews the literature on detection and remediation of clinical reasoning difficulties, and offers specific, practical steps for accurately diagnosing and quickly resolving identified problems with clinical reasoning. Faculties need to become more involved in the development and establishment of tools for encouraging direct observation of the development of clinical reasoning in medical learners, and for strengthening the teachers' pedagogical competencies.
\end{abstract}

Keywords: Clinical Reasoning; Remediation; Clinical Reasoning Difficulties; Faculty Development

\section{Introduction}

\section{Clinical Reasoning Is Central to Medical Practice}

Clinical reasoning stands at the very core of the medical profession. Defined as the set of complex thought and decision-making processes underlying clinicians' choices and actions in specific medical problem-solving contexts, clinical reasoning requires an array of cognitive, metacognitive, emotional, reflective thinking and relational skills (Higgs \& Jones, 2008).

An abundant literature on clinical reasoning theories and approaches exists. Recent summary articles that have reviewed the different approaches have contributed to clarifying the theoretical viewpoints, as well as their impact on teaching and evaluating of clinical reasoning (Croskerry, 2009; Eva, 2004; Nendaz, Charlin, Leblanc, \& Bordage, 2005).

To date, several authors have emphasized the importance of developing specific pedagogical approaches to facilitating the development of clinical reasoning during medical training. Building on the work of Kassirer (Kassirer, 1983), Barrows (Barrows \& Pickell, 1991), and others who have incorporated ideas stemming from cognitive psychology (and more specifically the organization of knowledge) (Regehr \& Norman, 1996; Tardif, 1992) and even social constructivism (Janssens et al., 2000), many authors have put forward practical strategies over the last few years, such as clinical reasoning team-based learning sessions and specific integrated supervisory strategies for

\footnotetext{
*Declaration of interest: The authors report no declarations of interest.
}

clarifying reasoning (Audétat \& Laurin, 2010b; Belleflamme, Boulouffe, Gérard, De Cannière, \& Vanpee, 2009; Borleffs, Custers, Van Gijn, \& Ten Cate, 2003; Bowen, 2006; Chamberland, 1998; Kassirer, 2010; Mc Hugh Schuster, 2000; Schuwirth, 2002; Struyf et al., 2005; Teherani, O’Sullivan, Aagaard, Morrison, \& Irby, 2007; Windish, 2000; Windish, price, Clever, Magaziner, \& Thomas, 2005; Wolpaw, Papp, \& Bordage, 2009). These strategies generally emphasize the importance of explicitly supporting the early development of clinical reasoning in authentic clinical contexts (Groves, 2005; Regehr \& Norman, 1996).

Ten to fifteen percent of medical students are identified as having academic difficulties (Faustinella, Orlando, Colletti, \& Perkowski, 2004; Yates \& James, 2006). Although different models exist in the literature to try to classify the various types of problems they encounter, there is general agreement that the main academic difficulties are cognitive in nature, including clinical reasoning difficulties (Catton et al., 2002; Faustinella et al., 2004; Hicks et al., 2005; Hu et al., 1989; Kassirer, 2010; Reamy \& Harman, 2006; Smith, Stevens, \& Servis, 2007).

In this paper, we review the current literature addressing the principal challenges related to identification and remediation of clinical reasoning in medical learners. In the first part, we will explore the challenges the educators face, according to published literature, in diagnosing clinical reasoning difficulties; in the second part, we will examine the extant research regarding potential strategies for remediating learners with clinical reasoning difficulties. Finally, we will highlight a certain number of actions that could be implemented to help diagnose clinical 
reasoning difficulties and resolve them quickly and accurately.

\section{Methods}

We searched the PubMed and MEDLINE databases for articles whose primary focus was the identification and/or remediation of clinical reasoning difficulties in medical learners. The research covers the 1995-2011 period. To conduct our review, we combined the following search terms: "clinical reasoning”, ”remedial teaching”, “clinical competence”, "learning”, "remediations”, "teaching”, "medical education”, "struggling medical students". We also assembled a comprehensive list of articles written by recognized medical education authors who have published on related subjects.

\section{Results \\ Identifying Trainees with Clinical Reasoning Difficulties}

Clinical reasoning difficulties are generally identified late in medical training (Frellsen, Baker, Papp, \& Durning, 2008; Hauer, Teherani, Kerr, O’Sullivan, \& Irby, 2007; Hicks et al., 2005). Although our review uncovered many reasons to explain this delay, three in particular were consistently raised and are worthy of specific mention:

1) Not much attention is given to observing students during their training years

Clinical teaching during the training years remains, for the most part, informal, tacit, and haphazard, and is contingent on the students' clinical exposure (Chamberland \& Hivon, 2005). Under these circumstances, there are often only limited opportunities to observe clinical skills during student training, and particularly during clerkship. The paucity of current reliable, valid, and feasible assessment tools may also contribute to clinician-educators' apparent disinclination to directly observe students' in-training performance (Hauer et al., 2009). Moreover, feedback is hardly ever based on actual observation of student interviews with patients (Dudek, Marks, \& Regehr, 2005; Hauer, Teherani, Irby, Kerr, \& O’Sullivan, 2008; Howley \& Wilson, 2004; Ludmerer, 2000).

2) The challenges of evaluation (including self evaluation)

Documenting and discussing problems with students pose additional challenges for educators who teach clinical reasoning. For instance, the final evaluation and the performance supervisor's opinion are often not consistent (Dudek et al., 2005). Dudek et al. (2005) point out that supervisors have a hard time documenting poor clinical performances, largely due to a lack of tools, of knowledge of what needs to be specifically identified, and of adequate means of remediation.

Add to this another problem: students are often required to evaluate their own performance, even though it has been shown that the correlation between self assessment and real performance is poor (Eva, Cunnington, Reiter, Keane, \& Norman, 2004; Regehr \& Eva, 2006).

3) The complexity of clinical reasoning

Clinical reasoning is inordinately complex. Although clinicians may have extensive knowledge and experience in a particular domain, they often have difficulty rendering the basics of their reasoning processes explicit during teaching. In a similar vein, clinician educators can quickly identify students with reasoning difficulties but often struggle to identify specifically where the problem lies (Audétat, Faguy, Jacques, Blais, \&
Charlin, 2011). It may be that they are not familiar with the underlying cognitive processes. Furthermore, the clinical reasoning literature is itself complex, and as a result most clinician teachers are not well acquainted with it (Dudek et al., 2005; Kempainen, Migeon, \& Wolf, 2003).

\section{Identifying Clinical Reasoning Difficulties in Trainees}

To shed light on the cognitive processes involved in clinical reasoning, and specifically the difficulties or pitfalls of reasoning in clinical contexts, two major paradigms have been advanced. These theoretical approaches are decision making (Chapman \& Sonnenberg, 2000; Hunink et al., 2001; Kahneman, Slovic, \& Tversky, 1982) and problem solving (Bordage \& Zacks, 1984; Elstein, Shulman, \& Sprafka, 1978; Schmidt, Norman, \& Boshuizen, 1990).

The decision making approach is concerned with the diagnosis and possible errors leading to a misdiagnosis. From this standpoint, reaching a diagnosis means updating opinion with imperfect information (the clinical evidence) (Elstein \& Schwartz, 2002; Hunink et al., 2001). The standard rule for this kind of task is Bayes' theorem. This theorem directs attention to two major classes of errors in clinical reasoning: errors in assessing à priori probability and errors in judging the strength of the evidence. Studies from the decision-making paradigm focus on errors in both components, like the potential biases resulting from the use of heuristics. Medical heuristics are mental shortcuts that are in most cases unconsciously used by clinicians to facilitate clinical decision making. They can lead to cognitive errors, such as availability, which is a common bias distorting hypothesis generation in judging the probability of an event on the basis of readily recalled similar events, or anchoring, which occurs when a doctor remains fixed on his first impression of a case, and fails to adjust hypotheses in light of new data. A widespread debate exists in the literature on strategies for avoiding these types of cognitive errors (Croskerry, 2003; Eva \& Norman, 2005; Mamede, Schmidt, \& Rikers, 2007; Mitchell, Russo, \& Pennington, 1989).

The problem solving approach views diagnostic reasoning as a process of hypothesis-testing. The solutions to complex problems are found by generating a limited number of hypotheses during the diagnostic process and subsequently using them to direct the collection of data. Each hypothesis can be used to predict which elements should be present if that hypothesis proves to be true. As a result, the diagnostic process is a focused search for features (findings) predicted by active hypotheses. From this perspective, errors that are likely to occur can, for instance, be related to the difficulty in generating correct hypotheses, the failure to identify present clinical clues or data, or the incorrect interpretation of these data (Bordage, 1999; Elstein \& Schwartz, 2002).

Errors or difficulties in clinical reasoning can also be contingent on the interpersonal or interactive aspects of the doctorpatient relationship. From this perspective, examples that can make clinical reasoning difficult include awkward interpersonal communication, poor integration of the reasoning of other professionals involved and the impact of the patient's personality on a negotiated approach to care (Higgs \& Jones, 2008).

Clinical reasoning difficulties are often correlated with performance in other domains, such as communication skills or professionalism (Hauer et al., 2007). This constitutes another major issue for teachers: identifying difficulties in multiple 
domains, understanding their intricate interrelationships, and prioritizing one or the other in a targeted remediation plan.

\section{Remediation of Clinical Reasoning Difficulties}

\section{General Findings on Remediation}

1) Established pedagogical principles

There is abundant literature on the pedagogical principles governing remediation in the clinical context (Gallant, MacDonald, \& Smith Higuchi, 2006; Hauer et al., 2007; Johnson, 2004; Perin, 2001; Steinert \& Lewitt, 1993; Szumacher et al., 2007). These studies suggest that effective remediation entails identifying difficulties early in the training curriculum, informing the students and instituting appropriate remediation measures. The remediation process should be student-centred and incorporate a thorough understanding of the student's difficulties and specific needs. It should be interactive and provided in a context that has significance for the learner. Lastly, the remediation process must be supported and valued by Faculty personnel and explicitly defined and guided by a person in charge.

\section{2) Limited remediation processes}

Beyond these general pedagogical principles, the remediation process in the frame of the training curriculum is not always clearly established. There is surprisingly little evidence to guide "best practices" of remediation in medical education, and it remains unclear how a lack of competence should be addressed before promotion. Medical education lags behind other areas of education in developing robust strategies for remediation.

In a recent article, Hauer et al. (2009) propose a response model composed of four key elements for implementing a successful remediation plan: 1) an initial evaluation using various evaluation tools to identify the difficulties; 2) an accurate diagnosis of the problems and the establishment of an individualized remediation plan; 3) instructions and activities that include specific clinical activities, feedback and reflective practice; and 4) a reassessment and a skill certification (Hauer et al., 2009).

3) The role of the clinician-educator in remediation

Teaching physicians take on two very specific roles: that of clinician responsible for the delivery of quality health care to patients, and that of educator responsible for helping students develop their clinical competencies, identifying and diagnosing possible difficulties, and implementing remediation means (Audétat, Laurin, \& Sanche, 2011; Irby, 1994; Kilminster, Cottrell, Grant, \& Jolly, 2007). Due to the realities of the clinical context, time constraints, and doubts as to the clinicianteachers' pedagogical competencies, it is sometimes difficult for them to take on both roles jointly. It is very tempting for clinicians to focus on the clinical role at the expense of their pedagogical responsibilities. In this context, "pedagogical reasoning", i.e. the approach that consists of collecting information, establishing a pedagogical diagnosis, establishing a remediation plan, implementing a remediation activity, and evaluating the results, is often lacking, which may fuel doubts and potential dissatisfaction on the part of clinician-teachers. (Audétat et al., 2011; Audétat \& Laurin, 2010a; Langlois \& Thach, 2000).

\section{Specific Remediations for Clinical Reasoning Difficulties}

There are relatively few descriptions of specific remediation methods (Chang, Chou, \& Hauer, 2008; Saxena, O’Sullivan, Teherani, Irby, \& Hauer, 2009). And there are very few publications on the effectiveness and validity of remediation plans dealing with clinical reasoning difficulties.

A few research papers focus on the perception of teachers with respect to remediation. In general, teachers have reservations about their actions and consider the process to be painstaking (Hauer et al., 2007). Several authors also emphasize the difficulty of determining which strategy is best suited to a given problem. They cite the multifactorial nature of difficulties added to teacher uncertainty with respect to the methods used in trying to explain it (Hauer et al., 2008; Saxena et al., 2009; Szumacher et al., 2007).

\section{Winning Strategies Identified}

When dealing with reasoning problems, the educator's focus should be on helping learners build strong knowledge structures and representations (e.g., schema, scripts, exemplars, and prototypes) (Bordage, 1994; Charlin, Boshuizen, Custers, \& Feltovich, 2007; Norman, 2005; Schmidt \& Rikers, 2007).

Some research has shown that integrated teaching of communication techniques and clinical reasoning in a clinical setting significantly fosters the development of clinical reasoning processes (Evans, Stanley, Mestrovic, \& Rose, 1991; Windish et al., 2005).

Remediation programs based on an integrated approach seem to provide interesting results. For instance, Chang et al. report the development of an effective remediation process: a $4^{\text {th }}$ year student 8-station CPX (clinical performance examination) with standardized patients helped evaluate clinical reasoning and communication competencies (Chang et al., 2008). A specific remediation program was then developed based on the following strategies: pedagogical diagnosis, faculty feedback and targeted supervision. The program included four specific steps: 1) individual review of recorded videos by the students, interview analysis and individualized development of improvement goals; 2) video review by a Faculty remediation director and development of an "official” pedagogical prescription (1 - 3 pages signed by the Faculty learning prescription); 3) planning of video screenings with a supervisor in accordance with the defined prescriptions; 4) competency strengthening and integration workshops in small groups, (theoretical contribution, clinical cases, role playing, analysis and integration). The evaluation of the impact of the process with participants shows that the most relevant elements were: practicing and analysing simulated interviews, learning to manage complex interviews (multiple diagnoses etc.), getting specific feedback from the supervisor and the Faculty, and having workshop discussions.

Research focused on gauging the improvement of clinical reasoning competencies (with respect to data collection and a targeted clinical exam related to the patient's complaint) evaluated the results of a very similar remediation process based on the same course of action. The exam given at the end of the four months of the remediation process indicated a $30 \%$ improvement with respect to the collection of data and $60 \%$ with respect to the clinical exam. The authors highlight the key role of the targeted exercises on clinical reasoning, the analysis and structure work provided by the videos and the formative feedback (Faustinella et al., 2004).

In general, participants have reported appreciation for the remediation strategies they underwent, and acknowledged their effectiveness (Ark, Brooks, \& Eva, 2007; Windish et al., 2005). All schemes require a large investment in terms of time and resources. 


\section{M.-C. AUDÉTAT ET AL.}

\section{Discussion}

Our review has shown that clinician-educators responsible for identification and remediation of clinical reasoning difficulties in medical learners face a set of important challenges. For example, precisely identifying the faulty step(s) along a learner's clinical reasoning pathway can be a formidable task, particularly for educators with limited familiarity with the current clinical reasoning literature. Even those educators who are wellversed in the theory of clinical reasoning and teaching methodology will attest that, to date, there exists no widely accepted framework or structured approach to identification and remediation of clinical reasoning deficits.

According to the literature, winning remediation strategies share the following critical elements: 1) an established pedagogical diagnosis, 2) faculty support, 3) a well-defined remediation plan or pedagogical prescription, and 4) the use of various verbalization and clinical reasoning structuring methods based on video recorded cases, role playing, standardized patients and targeted and directed supervision on clinical reasoning.

Early identification and early support, before the trainee or student runs into major difficulties, should be regarded as the gold standard for educational supervision (Evans, Alstead, \& Brown, 2010).

It thus appears crucial to implement a certain number of actions that will help diagnose clinical reasoning difficulties and resolve them quickly and accurately. To do so, we suggest that examining the following issues is critical:

\section{Direct Observation in the Clinical Context}

The data stemming from the literature very clearly underscore the need to directly observe students in their clinical context (Bowen, 2006; Evans et al., 2010; Schuwirth, 2002) with a view toward identifying and analyzing the clinical reasoning steps in the setting in which errors or difficulties arise (Groves, O’Rourke, \& Alexander, 2003). They also emphasize the importance of using a variety of tools for detecting specific difficulties and establishing a pedagogical diagnosis and remediation plan (Chang et al., 2008; Charlin, Bordage, \& Van Der Vleuten, 2003; Charlin, Gagnon, Sibert, \& Van der Vleuten, 2002; Faustinella et al., 2004; Hauer, Holmboe, \& Kogan, 2010; Smith, 2008). Students should also be encouraged to participate in deliberate (i.e., conscious and focused) practice and need to receive timely feedback on their performance (Ericsson, 2004).

\section{Deeper Understanding of Problems}

Considerable work needs to be done to better identify clinical reasoning difficulties, especially as they manifest in the clinical context. Therefore, it is necessary to develop not only a deeper understanding of the problems, but also an ability to better define them and model them. Disentangling multiple causes is necessary if we want to initiate appropriate remedial action.

"Attempting to understand resident performance without understanding factors that influence performance is analogous to examining patient adherence to medication regimens without understanding the individual patient and his/her environment" (Mitchell M et al., 2005).

Important work on associating theory and the realities of clinical practice needs to be carried out. The development of specific tools on evaluation and clinical reasoning difficulties will undoubtedly help clinician-teachers in their task of identifying and diagnosing problems.

\section{Better Pedagogical Equipment}

Clinician-teachers intuitively detect global difficulties in clinical reasoning exhibited by their students, but precise identification of the problem often remains difficult (Audétat et al., 2011). They do not feel effective in their remediations and have reservations about their competencies. Their actions are not necessarily part of an established pedagogical plan. It thus seems important to enhance the knowledge of clinician-teachers and their understanding of the multiple aspects of clinical reasoning (Bordage, 2007).

It is also important to acknowledge the dual role of clinicianteachers (clinical and pedagogical) and to boost their feeling of pedagogical competency (Evans et al., 2010; Irby, 1992). One way to do so would be to train them and increase their support in the clinical reasoning supervision process, but mainly in pedagogical reasoning with respect to the difficulties identified with students. Their remediation plans will then be better detailed, and as a result more likely to be effective (Mitchell et al., 2005; Steinert \& Lewitt, 1993; Vaughn, Baker, \& De Witt, 1998).

\section{More Faculty Support}

While the development of valid tools and the appropriate training of teachers are essential for identifying and remediating learners with clinical reasoning difficulties, the essential role of Faculties should not be overlooked.

Most Faculties in the health professions do not provide formal remediation interventions following summative evaluations (exams, end of training periods) or formative in-training evaluations. We can thus infer that some students reach the end of their training still struggling with clinical reasoning. It is therefore essential that the Faculties establish a framework and clear procedures for identifying and remediating learners with clinical reasoning difficulties throughout their training (Smith et al., 2007).

Based on our review, we advocate taking concrete steps to involve the Faculty in the pedagogical diagnosis and pedagogical prescription processes (Chang et al., 2008). Faculties have the potential to play an important role in offering support and advice to clinician-teachers for developing appropriate remediation strategies (Catton et al., 2002). It has been noted that when Faculties allocate more resources to remediation activities, teachers feel supported, more confident and more competent in their actions. The quality of the remediation process is improved (Saxena et al., 2009).

In response to these findings, the Family and Emergency Medicine Department of the University of Montreal has developed a multidimensional approach consisting of four prongs: implementing institutional procedures (Hauer et al., 2009) (e.g. regarding remediation plans and follow-up) (Sanche, Béland, \& Audétat, 2011), introducing clinical teachers to conceptual frameworks and empirical findings from the literature through accessible and targeted papers, developing remediation tools (e.g. a guide to the diagnosis and remediation of different types of clinical reasoning difficulties) (Audétat et al., 2012), and teacher-centered faculty development. Altogether this amounts 
to no less than a cultural (Audétat et al., 2012) and organizational change (Steinert, 2011) which should help clinician-teachers act effectively, based on well-grounded educational scripts (Côté \& Bordage, 2012) Arming clinician-teachers with a strong sense of "being clinical educators" (Higgs \& Mcallister, 2006) should ultimately improve outcomes for learners.

\section{Conclusion}

Many obstacles impede the rapid identification of clinical reasoning difficulties in medical learners, and more remediation methods are needed. There is also a need to implement structured identification and remediation processes for students in need. Furthermore, Faculties need to become more involved and encourage the development and establishment of tools that encourage direct observation of the development of clinical reasoning and strengthen the teachers' pedagogical competencies with respect to clinical reasoning per se, clinical supervision and the pedagogical diagnosis and remediation development processes. All this requires considerable time and substantial pedagogical and financial investment. However, faced with the reality of observing some students slip through the net and complete their medical training without being clinically competent, we suggest that there is an urgent need to commit ourselves in this direction. Intervening now will undoubtedly lead in time to improvements in patient care.

\section{REFERENCES}

Ark, T., Brooks, L., \& Eva, K. (2007). The benefits of flexibility: The pedagogical value of instructions to adopt multifaceted diagnostic reasoning strategies. Medical Education, 41, 281-287. doi:10.1111/j.1365-2929.2007.02688.x

Audétat, M., Laurin, S., Sanche, G., Béïque, C., Caire-Fon, N., Blais, J., \& Charlin, B. (2012). Clinical reasoning difficulties: A taxonomy for clinical teachers. Medical Teacher, 35, e984-e989.

Audétat, M. C., Dory, V., Nendaz, M., Vanpee, D., Pestiaux, D., Junod Perron, N., \& Charlin, B. (2012). What is so difficult about managing clinical reasoning difficulties? Medical Education, 46, 216-227. doi:10.1111/j.1365-2923.2011.04151.x

Audétat, M. C., Faguy, A., Jacques, A., Blais, J., \& Charlin, B. (2011). Exploratory study of perceptions and practices of clinical teachers engaged in a process of diagnosis and remediation of clinical reasoning difficulties. Pédagogie Médicale, 12, 7-16. doi:10.1051/pmed/2011014

Audétat, M. C., \& Laurin, S. (2010a). Clinician and supervisor, same challenge! Le Médecin du Québec, 45, 53-57.

Audétat, M. C., \& Laurin, S. (2010b). Supervision of clinical reasoning: Methods and a tool to support and promote clinical reasoning. Canadian Family Physician, 56, 127-129.

Audétat, M. C., Laurin, S., \& Sanche, G. (2011). Tackling clinical reasoning from a pedagogical perspective I. A conceptual framework to identify clinical reasoning problems. Pédagogie Médicale, 12.

Barrows, H., \& Pickell, G. (1991). Developing clinical problem-solving skills: A guide to more effective diagnosis and treatment. New York: Norton Medical Books.

Belleflamme, M., Boulouffe, C., Gérard, V., De Cannière, L., \& Vanpee, D. (2009). How can we foster our student's clinical reasoning when there is little time. Louvain Médical, 128, 165-169.

Bordage, G. (1994). Elaborated knowledge: A key to successful diagnostic thinking. Academic Medicine, 69, 883-885. doi:10.1097/00001888-199411000-00004

Bordage, G. (1999). Why did I miss the diagnosis? Some cognitive explanations and educational implications. Academic Medicine, 74, S138-S143. doi:10.1097/00001888-199910000-00065

Bordage, G. (2007). Prototypes and semantic qualifiers: From past to present. Medical Education, 41, 1117-1121. doi:10.1111/j.1365-2923.2007.02919.x

Bordage, G., \& Zacks, R. (1984). The structure of medical knowledge in the memories of medical students and general practitioners: Categories and prototypes. Medical Education, 18, 406-416. doi:10.1111/j.1365-2923.1984.tb01295.x

Borleffs, J., Custers, E., Van Gijn, J., \& Ten Cate, O. (2003). “Clinical reasoning theater": A new approach to clinical reasoning education. Medical Education, 78, 322-325. doi:10.1097/00001888-200303000-00017

Bowen, J. (2006). Educational strategies to promote clinical diagnostic reasoning. New England Journal of Medicine, 355, 2217-2225. doi:10.1056/NEJMra054782

Catton, P., et al. (2002). An academic difficulty in postgraduate medical education: Results of remedial progress at University of Toronto. The Annals of RCSC.

Chamberland, M. (1998). Learning sessions of clinical reasoning. Les Annales de Médecine Interne, 149, 479-484.

Chamberland, M., \& Hivon, R. (2005). Skills of clinical teachers and role models in clinical training. Pédagogie Médicale, 6, 98-111. doi:10.1051/pmed:2005015

Chang, A., Chou, C., \& Hauer, K. (2008). Clinical skills remedial training for medical education. Medical Education, 42, 1118-1119. doi:10.1111/j.1365-2923.2008.03191.x

Chapman, G., \& Sonnenberg, F. (2000). Decision making in health care: Theory, psychology, and applications. New York: Cambridge University Press.

Charlin, B., Bordage, G., \& Van Der Vleuten, C. (2003). Clinical reasoning evaluation. Pédagogie Médicale, 4, 42-52.

Charlin, B., Boshuizen, H., Custers, E., \& Feltovich, P. (2007). Scripts and clinical reasoning. Medical Education, 41, 1178-1184. doi:10.1111/j.1365-2923.2007.02924.x

Charlin, B., Gagnon, R., Sibert, L., \& Van der Vleuten, C. (2002). Script concordance test, a clinical reasoning evaluation tool. Pédagogie Médicale, 3, 135-144.

Côté, L., \& Bordage, G. (2012). Content and conceptual frameworks of preceptor feedback related to residents' educational needs. Academic Medicine, 87, 1274-1281. doi:10.1097/ACM.0b013e3182623073

Croskerry, P. (2009). A universal model of diagnostic reasoning. Academic Medicine, 84, 1022-1028. doi:10.1097/ACM.0b013e3181ace703

Croskerry, P. (2003). The importance of cognitive errors in diagnosis and strategies to minimize them. Academic Medicine, 78, 775-780. doi:10.1097/00001888-200308000-00003

Dudek, N., Marks, M., \& Regehr, G. (2005). Failure to fail: The perspectives of clinical supervisors. Academic Medicine, 80, S84-S87. doi:10.1097/00001888-200510001-00023

Elstein, A., \& Schwartz, A. (2002). Clinical problem solving and diagnostic decision-making: Selective review of the cognitive literature. British Medical Journal, 324, 729-732. doi:10.1136/bmj.324.7339.729

Elstein, A., Shulman, L., \& Sprafka, S. (1978). Medical problem solving: An analysis of clinical reasoning. Cambridge: Harvard University Press.

Ericsson, K. (2004). Deliberate practice and the acquisition and maintenance of expert performance in medicine and related domains. Academic Medicine, 79, S70-S81. doi:10.1097/00001888-200410001-00022

Eva, K. (2004). What every teacher needs to know about clinical reasoning. Medical Education, 39, 98-106. doi:10.1111/j.1365-2929.2004.01972.x

Eva, K., Cunnington, J., Reiter, H., Keane, D., \& Norman, G. (2004). How can I know what I don't know? Poor self assessment in a well-defined domain. Advances in Health Sciences Education, 9, 211-224. doi:10.1023/B:AHSE.0000038209.65714.d4

Eva, K., \& Norman, G. (2005). Heuristics and biases-A biased perspective on clinical reasoning. Medical Education, 39, 870-872. doi:10.1111/j.1365-2929.2005.02258.x

Evans, D., Alstead, E., \& Brown, J. (2010). Applying your clinical skills to students and trainees in academic difficulty. The Clinical 
Teacher, 7, 230-235. doi:10.1111/j.1743-498X.2010.00411.x

Evans, R., Stanley, R., Mestrovic, R., \& Rose, L. (1991). Effects of communication skills training on students' diagnostic efficiency. Medical Education, 25, 517-526. doi:10.1111/j.1365-2923.1991.tb00105.x

Faustinella, F., Orlando, P., Colletti, L., Juneja, H., \& Perkowski, L. (2004). Remediation strategies and students' clinical performance. Medical Teacher, 26, 664-665.

Frellsen, S. L. M. D., Baker, E. A. M. D. M., Papp, K. K. P., \& Durning, S. J. M. D. (2008). Medical school policies regarding struggling medical students during the internal medicine clerkships: Results of a national survey. Academic Medicine, 83, 876-881.

doi:10.1097/ACM.0b013e318181da98

Gallant, M., MacDonald, J.-A., \& Smith Higuchi, K. (2006). A remediation process for nursing students at risk for clinical failure. Nurse Educator, 31, 223-227. doi:10.1097/00006223-200609000-00010

Groves, M. (2005). Problem-based learning and learning approach: Is there a relationship? Advances in Health Sciences Education, 10, 315-326. doi:10.1007/s10459-005-8556-3

Groves, M., O'Rourke, P., \& Alexander, H. (2003). Clinical reasoning: The relative contribution of identification, interpretation and hypothesis errors to misdiagnosis. Medical Teacher, 25, 621-625. doi:10.1080/01421590310001605688

Hauer, K., Ciccone, A., Henzel, T., Katsufrakis, P., Miller, S., Norcross, W., \& Irby, D. (2009). Remediation of the deficiencies of physicians across the continuum from medical school to practice: A thematic review of the literature. Academic Medicine, 84, 1822-1832. doi:10.1097/ACM.0b013e3181bf3170

Hauer, K., Holmboe, E., \& Kogan, J. (2010). Twelve tips for implementing tools for direct observation of medical trainees' clinical skills during patient encounters. Medical Teacher, 2011, 27-33.

Hauer, K., Teherani, A., Irby, D., Kerr, K., \& O’Sullivan, P. (2008). Approaches to medical student remediation after a comprehensive clinical skills examination. Medical Education, 42, 104-112. doi:10.1111/j.1365-2923.2007.02937.x

Hauer, K., Teherani, A., Kerr, K., O'Sullivan, P., \& Irby, D. (2007). Student performance problems in medical school clinical skills assessments. Academic Medicine, 82, S69-S72.

Hicks, P. J., Cox, S. M., Espey, E. L., Goepfert, A. R., Bienstock, J. L., Erickson, S. S., \& Puscheck, E. E. (2005). To the point: Medical education reviews-Dealing with student difficulties in the clinical setting. American Journal of Obstetrics and Gynecology, 193, 19151922. doi:10.1016/j.ajog.2005.08.012

Higgs, J., \& Jones, M. (2008). Chapter 1: Clinical decision making and multiple problem spaces. In J. Higgs, \& M. Jones (Eds.), Clinical Reasoning in the Health Professions (pp. 3-17). Oxford: ButterworthHeineman Ltd.

Higgs, J., \& Mcallister, L. (2006). Being a clinical educator. Advances in Health Sciences Education, 12, 187. doi:10.1007/s10459-005-5491-2

Howley, L., \& Wilson, W. (2004). Direct observation of students during clerkship rotations: A multi-year descriptive study. Academic Medicine, 79, 276-280. doi:10.1097/00001888-200403000-00017

Hunink, M., Glasziou, P., Siegel, J., Weeks. J., Pliskin, J., Elstein, A. S., \& Elstein. A. S. (2001). Decision making in health and medicine: Integrating evidence and values. New York: Cambridge University Press.

Hunt, D. D., Carline, J., Tonesk, X., Yergan, J., Siever, M., \& Loebel, J. (1989). Types of problems students encountered by clinical teachers and clerkships. Medical Education, 23, 14-18. doi:10.1111/j.1365-2923.1989.tb00806.x

Irby, D. (1994). What clinical teachers need to know. Academic Medicine, 69, 333-342. doi:10.1097/00001888-199405000-00003

Irby, D. M. (1992). How attending physicians make instructional decisions when conducting teaching rounds. Academic Medicine, 67, 630-638. doi:10.1097/00001888-199210000-00002

Janssens, S., Verschaffel, L., De Corte, E., Elen, J., Lowyck, J., Struyf, E., \& Vandenberghe, R. (2000). Didactics on the move.

Johnson, G. (2004). Constructivist remediation: Correction in context. International Journal of Special Education, 19, 72-88.
Kahneman, D., Slovic, P., \& Tversky, A. (1982). Judgment under uncertainty: Heuristics and biases. New York: Cambridge University Press. doi:10.1017/CBO9780511809477

Kassirer, J. (1983). Teaching clinical medicine by iterative hypothesis testing: Let's preach what we practice. The New England Journal of Medicine, 309, 921-923.

Kassirer, J. (2010). Teaching clinical reasoning: Case-based and coached. Academic Medicine, 85, 1118-1124. doi:10.1097/ACM.0b013e3181d5dd0d

Kempainen, R., Migeon, M., \& Wolf, F. (2003). Understanding our mistakes: A primer on errors in clinical reasoning. Medical Teacher, 25, 177-181. doi:10.1080/0142159031000092580

Kilminster, S., Cottrell, D., Grant, J., \& Jolly, B. (2007). AMEE guide No. 27: Effective educational and clinical supervision. Medical Teacher, 29, 2-19. doi:10.1080/01421590701210907

Langlois, J. P., \& Thach, S. (2000). Preventing the difficult learning situation. Family Medicine, 32, 232-234.

Ludmerer, K. (2000). Time and medical education. Annals of Internal Medicine, 132, 25-27. doi:10.7326/0003-4819-132-1-200001040-00005

Mamede, S., Schmidt, H., \& Rikers, R. (2007). Diagnostic errors and reflective practice in medicine. Journal of Evaluation in Clinical Practice, 13, 138-145. doi:10.1111/j.1365-2753.2006.00638.x

Mitchell, D., Russo, J., \& Pennington, N. (1989). Back to the future: Temporal perspective in the explanation of events. Journal of Behavioral Decision Making, 2, 25-38. doi:10.1002/bdm.3960020103

Mitchell, M., Srinivasan, M., West, D. C., Franks, P., Keenan, C., \& Henderson, M. (2005). Factors affecting resident performance: Development of a theoretical model and a focused literature review. Academic Medicine, 80, 376-389.

doi:10.1097/00001888-200504000-00016

Nendaz, M., Charlin, B., Leblanc, V., \& Bordage, G. (2005). Le raisonnement clinique: Données issues de la recherche et implications pour l'enseignement. Pédagogie Médicale, 6, 235-254. doi:10.1051/pmed:2005028

Norman, G. (2005). Research in clinical reasoning: Past history and current trends. Medical Education, 39, 418-427. doi:10.1111/j.1365-2929.2005.02127.x

Perin, D. (2001). Making remediation more learner-centered: Promising approaches from case studies. Community College Journal, 72, 5356.

Reamy, B., \& Harman, J. (2006). Residents in trouble: An in-depth assessment of the 25-year experience of a single family medicine residency. Family Medicine, 38, 252-257.

Regehr, G., \& Eva, K. (2006). Self-assessment, self-direction, and the self-regulating professional. Clinical orthopaedics and related research, 449, 34-38.

Regehr, G., \& Norman, G. (1996). Issues in cognitive psychology: Implication for professional education. Academic Medicine, 71, 9881001. doi:10.1097/00001888-199609000-00015

Sanche, G., Béland, N., \& Audétat, M. C. (2011). La création et l'implantation réussie d'un outil de remédiation en résidence de médecine familiale. Le Médecin de famille canadien, 57, e468-e472.

Saxena, V., O’Sullivan, P., Teherani, A., Irby, D., \& Hauer, K. (2009). Remediation techniques for student performance problems after a comprehensive clinical skills assessment. Academic Medicine, 84, 669-676.

Schmidt, H., Norman, G., \& Boshuizen, H. (1990). A cognitive perspective on medical expertise: Theory and implications. Academic Medicine, 65, 611-621. doi:10.1097/00001888-199010000-00001

Schmidt, H., \& Rikers, R. (2007). How expertise develops in medicine: Knowledge encapsulation and illness script formation. Medical Education, 41, 1133-1139.

Schuster, P. M. (2000). Concept mapping: Reducing clinical care plan paperwork and increasing learning. Nurse Educator, 25, 76-81.

Schuwirth, L. (2002). Can clinical reasoning be taught or can it only be learned? Medical Education, 36, 695-696. doi:10.1046/j.1365-2923.2002.01274.x

Smith, C. S. (2008). A developmental approach to evaluating competence in clinical reasoning. Journal of Veterinary Medical Educa- 
tion, 35, 375-381. doi:10.3138/jvme.35.3.375

Smith, C. S., Stevens, N., \& Servis, M. (2007). A general framework for approaching residents in difficulty. Family Medicine, 39, 331336.

Steinert, Y. (2011). Commentary: Faculty development: The road less traveled. Academic Medicine, 86, 409-411. doi:10.1097/ACM.0b013e31820c6fd3

Steinert, Y., \& Lewitt, C. (1993). Working with the "problem” resident: Guidelines for definition and intervention. Family Medicine, 25, 627632.

Struyf, E., Beullens, B., Van Damme, B., Janssen, P., \& Jaspaert, H. (2005). A new methodology for teaching clinical reasoning skills: Problem solving clinical seminars. Medical Teacher, 27, 364-368. doi:10.1080/01421590500046411

Szumacher, E., Catton, P., Jones, G., Bradley, R., Kwan, J., Cherryman, F., \& Nyhof-Young, J. (2007). Helping learners in difficulty-The incidence and effectiveness of remedial programmes of the medical radiation sciences programme at University of Toronto and the Michener Institute for applied sciences, Toronto, Ontario, Canada. Annals of the Academy of Medicine, Singapore, 36, 725-734.

Tardif, J. (1992). Pour un enseignement stratégique: L'apport de la psychologie cognitive. Montréal: Les Éditions Logiques.
Teherani, A., O’Sullivan, P., Aagaard, E., Morrison, E., \& Irby, D. (2007). Student perceptions of the one minute preceptor and traditional preceptor models. Medical Teacher, 29, 323-327. doi:10.1080/01421590701287988

Vaughn, L., Baker, R., \& De Witt, T. (1998). The problem learner. Teaching and Learning in Medicine, 10, 217-222. doi:10.1207/S15328015TLM1004 4

Windish, D. (2000). Teaching medical students clinical reasoning skills. Academic Medicine, 75, 90. doi:10.1097/00001888-200001000-00022

Windish, D., Price, E., Clever, S., Magaziner, J., \& Thomas, P. (2005). Teaching medical students the important connection between communication and clinical reasoning. Journal of General Internal Medicine, 20, 1108-1113.

Wolpaw, T., Papp, K., \& Bordage, G. (2009). Using SNAPPS to facilitate the expression of clinical reasoning und uncertainties: A randomized comparison group trial. Academic Medicine, 84, 517-524. doi:10.1097/ACM.0b013e31819a8cbf

Yates, J., \& James, D. (2006). Predicting the "strugglers": A casecontrol study of students at Nottingham University Medical School. British Medical Journal, 332, 1009-1013.

doi:10.1136/bmj.38730.678310.63 